\title{
Article \\ Deformation of Stacked Metallic Sheets by Shock Wave Loading
}

\author{
Sandeep P. Patil ${ }^{1, *}$ (D), Rahul Murkute ${ }^{1,2}$ and Nima Shirafkan ${ }^{1}$ and Bernd Markert ${ }^{1}$ \\ 1 Institute of General Mechanics, RWTH Aachen University, Templergraben 64, 52062 Aachen, Germany; \\ rahul.murkute@st.ovgu.de (R.M.); nima@iam.rwth-aachen.de (N.S.); markert@iam.rwth-aachen.de (B.M.) \\ 2 Institute of Fluid Dynamics and Thermodynamics, Otto von Guericke University Magdeburg, \\ Universitätsplatz 2, 39106 Magdeburg, Germany \\ * Correspondence: patil@iam.rwth-aachen.de; Tel.: +49-241-809-0036
}

Received: 2 August 2018; Accepted: 24 August 2018; Published: 29 August 2018

\begin{abstract}
The focus of the present work is to develop a deep understanding of deformation of stacked metal sheets with a series of different sequences by using shock wave loading. Here, experimental and numerical investigations of deformation of a single metal sheet of $1.5-\mathrm{mm}$ and the stack of three metal sheets of $0.5-\mathrm{mm}$ thickness of aluminum $(\mathrm{Al})$, copper $(\mathrm{Cu})$ and brass $(\mathrm{Br})$ material were carried out. In the shock wave experiments, helium was used as the driving gas to produce a strong shock wave. Finite elements method (FEM) simulations on 3D-computational models were performed with explicit dynamic analysis, and Johnson-Cook material model was used. The obtained results from experiments of the outer diameter, thickness distribution, and dome height were analyzed and compared with the numerical simulations, and both the results are in excellent agreement. Moreover, for the same pressure load, due to lower inter-metallic friction in the stacked sheets compared to a cohesive property of the single sheet, an excellent deformation of stacked metallic sheets was observed. The results of this work indicated that the shock wave-forming process is a feasible technique for mass production of stacked metallic sheets as well as fabricating a hierarchical composite structure, which provides higher formability and smooth thickness distribution compared to a single material.
\end{abstract}

Keywords: shock wave tube; finite element method; stacked metallic sheets

\section{Introduction}

High-speed forming is a widely investigated technique, which refers to a forming process whereby the workpiece material experiences the high forming speed of up to several hundred meters per second. In high-speed forming processes, such as explosive, gas detonation, electromagnetic, electrohydraulic and shock tube forming, a plate is plastically deformed by means of high kinetic energy. These modern techniques provide productive usage of material, energy sources and minimize the problem which comes around in the formation of a sheet metal [1]. Shock waves are mechanical waves of finite amplitudes and rise when a matter is subjected to a rapid compression [2]. Due to sudden changes in velocity and pressure, the shock wave gained effective usage and application in an area such as physics, chemistry, materials science, engineering, military technology, medicine, and several other areas $[3,4]$.

Shock waves produced by shock tube have a higher degree of formability for various materials, which are capable of forming complex geometries, undercuts, and fine embossing without relief angle. The process consists of clean combustion, having the advantages of easy automation and fewer safety regulations. The cost for a small part or component is remarkably minimized due to reduced tooling requirement compared to electromagnetic forming [5]. Recently, sheet metal forming has attracted 
great research attention in the stretching and bending of a thin sheet into the desired shape. Due to its stiffness and good strength-to-weight ratios, it is widely used in trains, passenger cars, domestic planes, aircraft, rockets and food and drinks cans [6].

In previous works, Kumar et al. [7] conducted experimental and numerical studies to understand the effect of three different radii of plate curvature on shock tube for aluminum panels. A 3D Digital Image Correlation technique (DIC) is used to obtain deflection, velocity and in-plane strains. The result showed that the plane with maximum radius curvature had the least plastic deformation [7]. Ray et al. [8] investigated the microstructure, texture, and hardness of AA5086 aluminum for different loading condition by three different sizes of specific diaphragms using shock wave tube for the unidirectional manner and multi-step cross rolling process. Duan et al. [9] investigated the flow structures, propagation and theoretical critical pressure for ignition of generated shock waves using different dimensions of a tube and different pressures [9].

Reddy et al. [10] investigated the behavior of composite sandwich panels against different shock loads to report the fabrication of sandwich panels using E-glass-epoxy composite face sheet and aluminum foam. Also, failure behavior of aluminum foam and sandwich material were studied [10]. Ruan et al. [11] designed experimental equipment to examine the forming of magnesium alloy in cold working using underwater shock waves. Their experimental results revealed the increase in coefficient of extension and hardness of materials after receiving a shock wave [11]. Louar et al. [12] studied the incident and reflected pressure time signal measurements for the different amount of C4 charges. Their investigations were focused on the use of one explosive drive shock tube (EDST) and achieved results from a series of tests using EDST were discussed [12]. Nagaraja et al. [13] studied the deformation of thin metallic plates/foils, which were subjected to shock wave loading in the newly developed diaphragm-less shock tube. Aluminum, copper and brass plates of 60-mm diameter with different thicknesses and pressures were tested [13].

Atrian et al. [14] research work was concerned with the experimental and finite element method of deep drawing process steel and laminated brass sheets. Different tests were conducted with an influence of some variables like stacking sequence of the layers, lubrication, blank-holder force and the diameter of the composite blank on the load-displacement curve and the final shape of the produced components. The results showed the investigation of stress and strain distributions for finite element study and the experimental tests [14]. Andreotti et al. [15] studied the numerical approach for the performance of a double diaphragm using shock tube and structural response. Justusson et al. [16] and Aune et al. $[17,18]$ investigated the use of shock tubes to deform the metal plates plastically. Stoffel et al. $[19,20]$ reported work on numerical simulation and experimental validation of plates subjected to impulsive loading. In our previous work, we have studied DC04 metal forming using gas detonation forming process experimentally and numerically. Wherein, investigation of detonation pressure, deformed cup, thickness distribution, radial strain and damage in a cup were studied [21-23].

The above studies suggest that the substantial progress has been made in the research area of a shock wave, however, to the best of authors' knowledge, there has been no reported work on stacked metallic sheets subjected to high-pressure wave using shock wave tube. In high-speed metal forming, the very high pressure is applied on the workpiece. Therefore, in the case of the final deformed shape is not complicated, the stack of workpieces can be deformed together. Moreover, any combination of different materials can be formed simultaneously, to save time as well as energy. However, to optimize such a forming process in industry, knowledge of material behavior under very high pressure and deformation rates is required. Also, a comparison study of the mechanical behavior of single and stacked metal sheets against high-pressure waves needed to investigate. In present work, experimental and numerical investigations of deformation of a single metal sheet of $1.5-\mathrm{mm}$ and stacked metallic sheets with a thickness of $0.5-\mathrm{mm}$ of aluminum $(\mathrm{Al})$, copper $(\mathrm{Cu})$ and brass $(\mathrm{Br})$ with different sequence are carried out. Moreover, dome height, outer diameter, and thickness distribution results of deformed metallic sheets obtained from experiments and simulations are investigated and discussed. Furthermore, during the deformation process, the strain and stress distribution in the sheets 
are studied. Finally, based on the numerical and experimental observation, some useful conclusions are made, and extension of this work is proposed.

\section{Methodologies}

\subsection{Experimental Setup}

A schematic representation of a shock wave tube is shown in Figure 1. Shock tube consists of a high-pressure chamber (HPC), which can be filled with different gases, and a low-pressure chamber (LPC), which is separated from the HPC by a membrane. A plate specimen is clamped between two rings, and a fixed die is located at the end of the tube. The workpiece is not fixed between these rings. However, it is in the groove of the die. Therefore, it is free to move in the horizontal plane. During the experiment, the inside pressure of the HPC increases and after the burst of the membrane, the shock wave propagates into the LPC, and finally reaches to the plate specimen followed by a reflection. Owing to wave impact and reflection, the plate starts to deform. The history of the pressure was measured by piezoelectric sensors, which were located in a separate ring flange in front of the specimen and specialized in recording fast changes of pressure. The type of sensor used was Kistler 603B (Kistler Instrumente $\mathrm{GmbH}$, Sindelfingen, Germany). Figure 1 illustrates the respective position of the sensors. Depending on the type of gas in the HPC, the length of tube parts and type of the membrane material and thickness, different evolutions of the pressure history can be generated. Here, the shock wave tube consists of a $5.5 \mathrm{~m}$ long HPC section with internal diameter $80 \mathrm{~mm}$ and a $6.5 \mathrm{~m}$ long LPC section with internal diameter $108 \mathrm{~mm}$ and a $15 \mathrm{~mm}$ thick wall for both the sections. One small hole was drilled through a die, which was connected to a vacuum pump, to prevent the formation of air trap between the sheet metal and the die. The stacked metal sheets were mounted in a specially designed holder attached at the end of the shock tube.

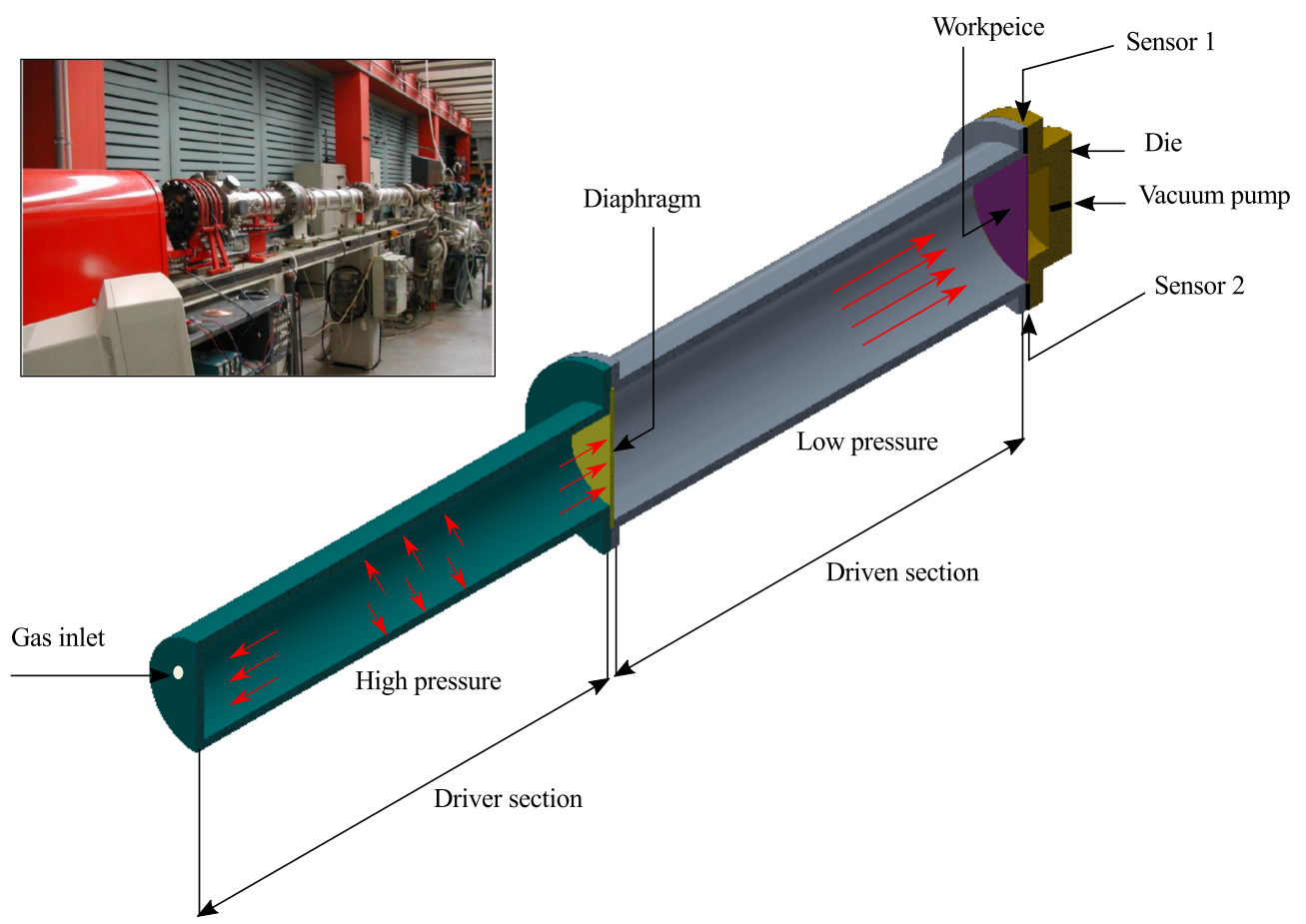

Figure 1. A schematic representation the experimental setup of the shock wave tube forming process. Inset: The shock tube facility at the Institute of General Mechanics, RWTH Aachen University.

Figure 2 shows the dimensions of the die. The diameter of the circular metal blank was $138 \mathrm{~mm}$, and the inner diameter of the die was considered $90 \mathrm{~mm}$. The stack of metal sheets placed with thin papers in between them to minimize wrinkles due to a small gap between the die and the holder. 


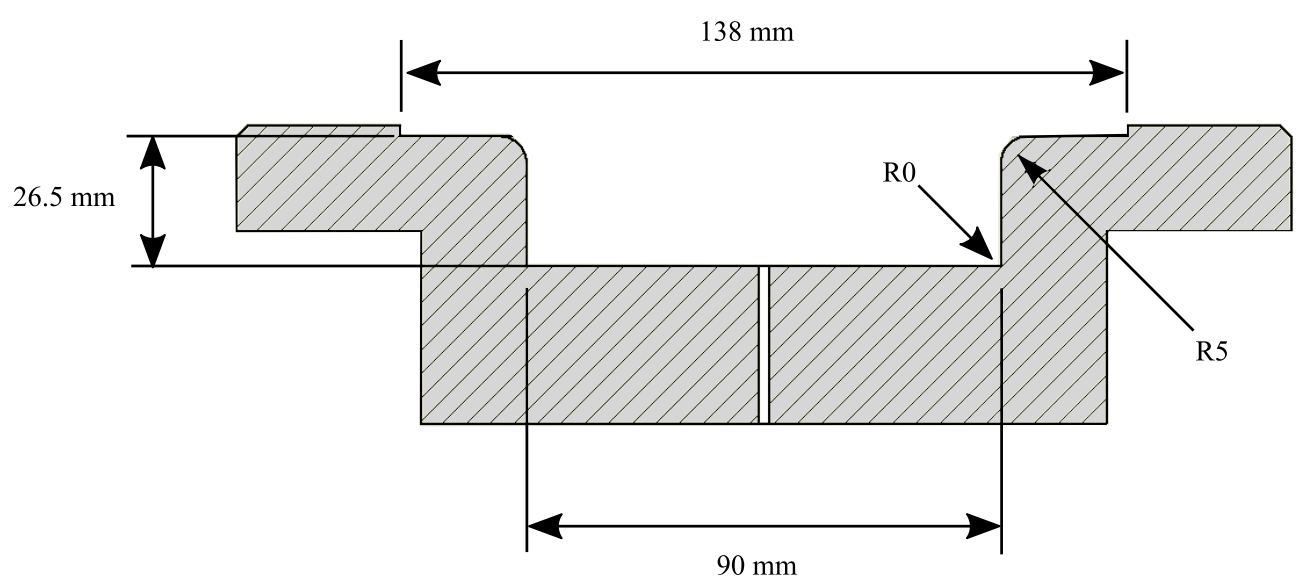

Figure 2. Dimensions of the die.

The driven and driver section of the tube was evacuated and maintained at room temperature. The driver section was filled with enough helium gas until it reaches to a critical pressure to burst the membrane. To keep the pressure between $38-40$ bar, the total thickness of the diaphragm used was $600 \mu \mathrm{m}$ (three hostophan membranes with $200 \mu \mathrm{m}$ thickness of each membrane). The maximum loading pressure on a metallic plate was recorded approximately 37-39 bar. A shock wave formed after the rupture of the diaphragm, wave traveled towards the end of a driven section within a very short interval of time with a constant supersonic velocity, which hit the metal sheets and reflects it back. The reflected wave with lower pressure than incident shock pressure, which moves back until it reaches the contact surface separating the driver and driven gas [24]. The maximum pressure acting on the metallic sheets was observed nearly $3 / 4$ th time of the initial pressure.

In the present work, a series of experiments were carried out for stacked metal sheets of $\mathrm{Al}, \mathrm{Cu}$, and $\mathrm{Br}$. For the thickness of $0.5-\mathrm{mm}$, stack of three metal sheets with 9 different combinations were considered. The chemical compositions of $\mathrm{Al}, \mathrm{Cu}$, and $\mathrm{Br}$ are given in Table 1 and stacked of metallic sheets with a different combination in Table 2.

Table 1. The chemical composition of $\mathrm{Al}, \mathrm{Cu}$ and $\mathrm{Br}$.

\begin{tabular}{cccccccccccc}
\hline \multirow{2}{*}{ Material } & \multicolumn{10}{c}{ Composition wt $\%$} \\
\cline { 2 - 11 } & $\mathbf{C u}$ & $\mathbf{M g}$ & $\mathbf{M n}$ & $\mathbf{F e}$ & $\mathbf{S i}$ & $\mathbf{T i}$ & $\mathbf{N i}$ & $\mathbf{P b}$ & $\mathbf{O 2}$ & $\mathbf{Z n}$ \\
\hline AA5754 & - & 3.2 & 0.2 & 0.3 & 0.06 & 0.01 & - & - & - & - \\
CuZn37 & 65.5 & - & - & $<0.1$ & - & - & $<0.3$ & $<0.1$ & - & rest \\
OHFC Cu & 99.99 & - & - & - & - & - & - & - & 0.001 & - \\
\hline
\end{tabular}

Table 2. The stacked of metal sheets with a series sequences.

\begin{tabular}{cccccccccc}
\hline \multirow{2}{*}{ Metal Sheet } & \multicolumn{10}{c}{ Sequences } \\
\cline { 2 - 10 } & $\mathbf{1}$ & $\mathbf{2}$ & $\mathbf{3}$ & $\mathbf{4}$ & $\mathbf{5}$ & $\mathbf{6}$ & $\mathbf{7}$ & $\mathbf{8}$ & $\mathbf{9}$ \\
\hline top sheet & $\mathrm{Al}$ & $\mathrm{Br}$ & $\mathrm{Cu}$ & $\mathrm{Al}$ & $\mathrm{Cu}$ & $\mathrm{Br}$ & $\mathrm{Cu}$ & $\mathrm{Br}$ & $\mathrm{Al}$ \\
middle sheet & $\mathrm{Cu}$ & $\mathrm{Cu}$ & $\mathrm{Cu}$ & $\mathrm{Br}$ & $\mathrm{Br}$ & $\mathrm{Br}$ & $\mathrm{Al}$ & $\mathrm{Al}$ & $\mathrm{Al}$ \\
bottom sheet & $\mathrm{Br}$ & $\mathrm{Al}$ & $\mathrm{Cu}$ & $\mathrm{Cu}$ & $\mathrm{Al}$ & $\mathrm{Br}$ & $\mathrm{Br}$ & $\mathrm{Cu}$ & $\mathrm{Al}$ \\
\hline
\end{tabular}

Figure 3 represents the simplest form of an ideal blast wave pressure profile, which is described as the Friedlander waveform curve, and actual pressure-time history for a shock wave in the tube. All experiments were conducted at the shock wave laboratory, Institute of General Mechanics, RWTH Aachen University. 

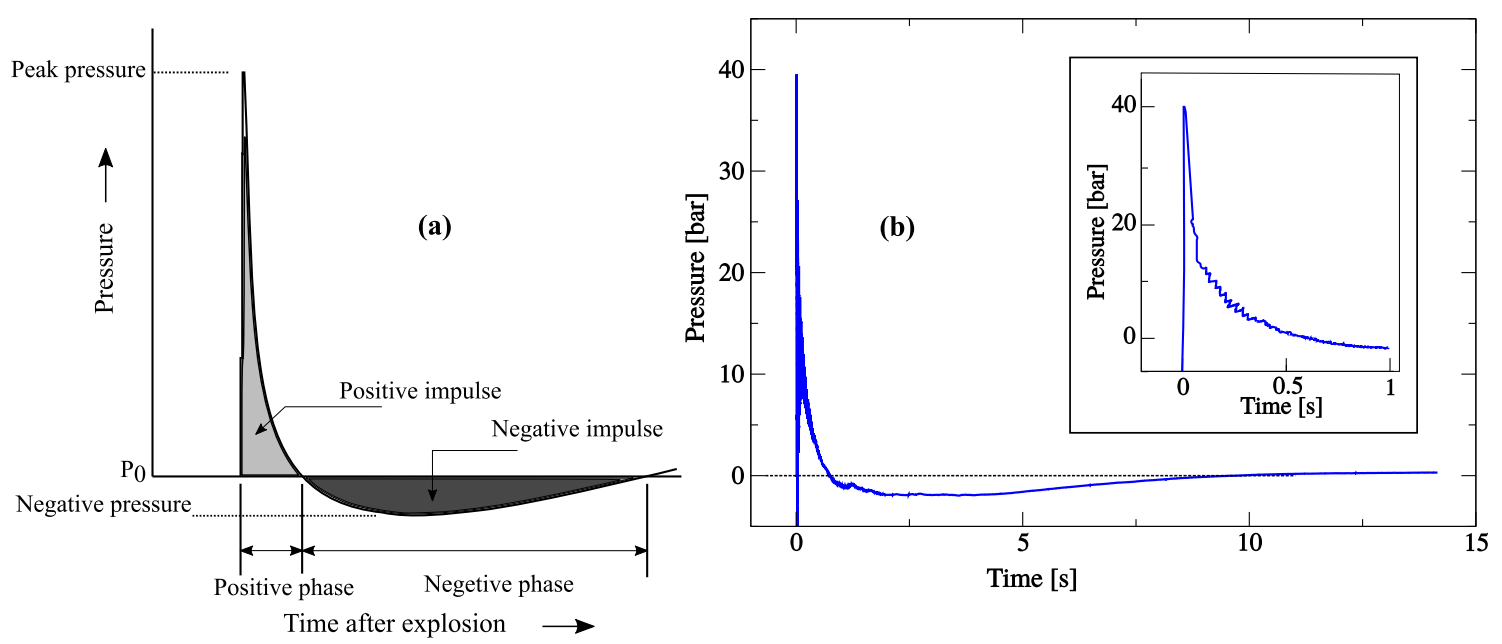

Figure 3. (a) A schematic representation of an ideal blast wave pressure profile. (b) The actual pressure-time history for a shock wave in the tube. Inset: Enlarge view of the time range between 0 and $1 \mathrm{~s}$.

\subsection{Material and Modeling}

A numerical simulation is a powerful tool for analysis of sheet forming process. It is based on the solution of dynamic equilibrium equations. Numerical simulations were performed by using an explicit time integration in LS-DYNA (Livermore Software Technology Corporation (LSTC), San Francisco, CA, USA) solver [25]. As the goal of this work was to study the deformation process of sheet metal, we were not interested in shock wave propagation in a shock tube. This process has made more comprehensible by directly applying the shock wave pressure as a pressure load in the finite element (FE) model as shown in Figure 4.

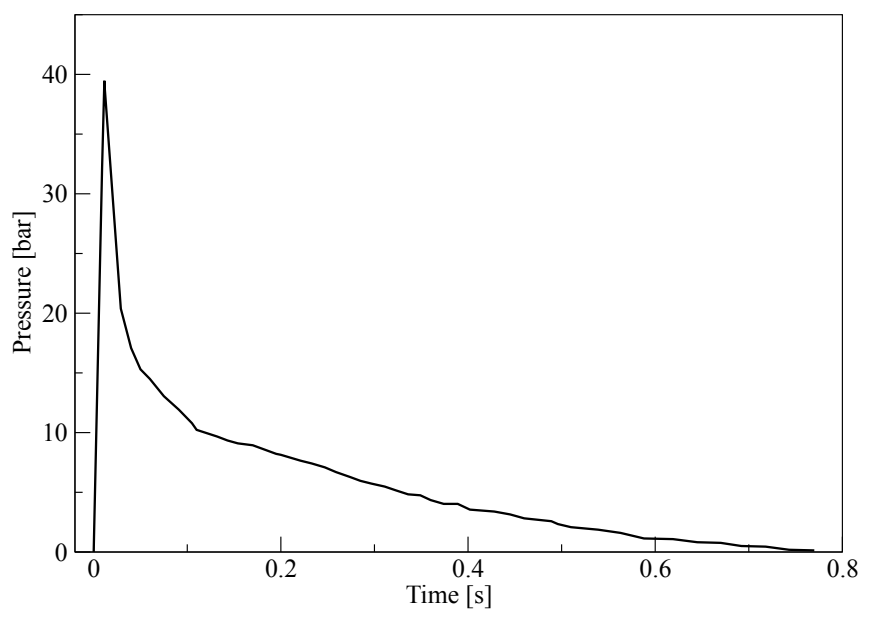

Figure 4. Pressure-time load curve used for simulation.

The full model was considered for finite element simulation to study the deep deformation of the stacked metallic sheets with different combinations and single metal plate. The model includes the die, holder and metal sheets as a workpiece. Figure 5 shows the half section view with stacked metal sheets. The die and holders components were represented as the solid elements and assigned them with rigid material (MAT_20) model. Belytschko-Tsay shell with five integration points [25] were used to create the mesh on the metal plate. The boundary nodes of the workpieces are kept free to move in the horizontal plane to mimic the clamping in the experiments. We conducted simulations for a different number of elements from very coarse to very fine model $(\sim 41125, \sim 62154, \sim 80158$, 
111665), wherein the coarse mesh has maximum stress near the critical areas like die curvature and center area of the plate, due to which formability of sheets was not smooth. As the number of elements increases, internal energy also increases. Therefore, to minimize the critical stress, metal sheet was divided into four different element sizes, near the center area with $0.15 \mathrm{~mm}$, in the middle area of sheet with $0.35 \mathrm{~mm}$, die curvature with $0.23 \mathrm{~mm}$ and outer area of the sheet with $0.86 \mathrm{~mm}$. Thus, a total number of elements on a single metal sheet was 111665, and for the three metal sheets, the total number of elements were 334995. The die and holders were fixed, and a segment-based surface-to-surface contact formulation was used to define between them [25]. The mechanical properties of the $\mathrm{Al}, \mathrm{Cu}$, and $\mathrm{Br}$ are given in Table 3 [26].
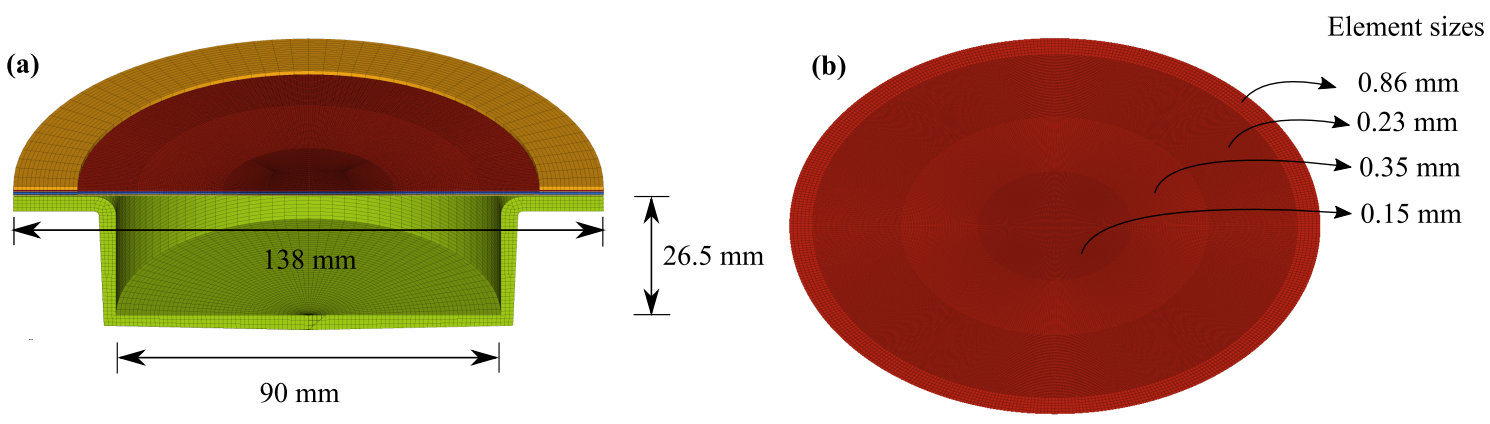

Figure 5. (a) Half section view of the 3D FE model. (b) Mesh density of workpiece.

Table 3. Mechanical properties of $\mathrm{Al}, \mathrm{Cu}, \mathrm{Br}[26]$.

\begin{tabular}{cccc}
\hline Property & Aluminum & Copper & Brass \\
\hline Young's Modulus (MPa) & 68,900 & 116,000 & 110,000 \\
Shear Modulus (MPa) & 26,000 & 48,000 & 41,000 \\
Density (kg/m3) & 2700 & 8980 & 8520 \\
Poisson's Ratio & 0.33 & 0.34 & 0.31 \\
\hline
\end{tabular}

The Johnson-Cook phenomenological material model (MAT_015) [27] was used as a material model for the metal sheets. The model is able to predict the mechanical behavior of the material under different loading conditions. In this model, strain hardening, strain rate sensitivity and thermal softening are considered as the three key characteristics of the material. These three effects are combined in a multiplication manner, such that the Johnson-Cook constitutive stress reads

$$
\sigma_{y}=\left(A+B \bar{\varepsilon}^{p^{n}}\right)\left(1+C \ln \frac{\dot{\bar{\varepsilon}}^{p}}{\dot{\varepsilon}_{0}}\right)\left(1-\left[\frac{T-T_{\text {room }}}{T_{\text {melt }}-T_{\text {room }}}\right]^{m}\right),
$$

where $A$ is the elastic limit strength and fixes the stress value at which the plastic behavior starts, $B$ and $n$ are the work hardening parameters and influence the slope of the flow stress in the plastic domain. The parameter $n$ usually assumes values between 0 (for the perfectly plastic model) and 1 (for a bilinear model). $C$ is the strain rate sensitivity coefficient, and $m$ describes the thermal softening. $\dot{\varepsilon}_{0}$ represents the strain rate for the quasi-reference loading.

The expression of a first set bracket in Equation (1) represents the stress as a function of strain. Where, parameters $A, B$ and $n$ can be determined using static tensile test. The expression of second bracket set represents an effect of strain rate hardening with the parameter $C$. The last set of expression represents the temperature sensitivity. The required material parameters for the simulations are given in Table 4 [27-30]. Hence the different static (SF) and dynamic friction (DF) coefficients were considered between the workpiece, holder and die. From the literature, the considered friction parameters were Al-die (SF =0.421, $\mathrm{DF}=0.33), \mathrm{Al}-\mathrm{Al}(\mathrm{SF}=0.405, \mathrm{DF}=0.418), \mathrm{Br}-\mathrm{die}(\mathrm{SF}=0.2, \mathrm{DF}=0.3)$, $\mathrm{Br}-\mathrm{Br}(\mathrm{SF}=\mathrm{DF}=0.5), \mathrm{Cu}-\mathrm{Cu}(\mathrm{SF}=1.0, \mathrm{DF}=1.1), \mathrm{Cu}$-die $(\mathrm{SF}=0.53, \mathrm{DF}=0.36), \mathrm{Al}-\mathrm{Cu}(\mathrm{SF}=0.35$, $\mathrm{DF}=0.25)$ and $\mathrm{Al}-\mathrm{Br}$ and $\mathrm{Br}-\mathrm{Cu}(\mathrm{SF}=0.5, \mathrm{DF} 0.5)$ [31-38]. For these simulations, no significant 
variations were observed in the deformation of workpiece with the variation of static and dynamic friction coefficient values.

Table 4. Values for the Johnson-Cook material model parameters for $\mathrm{Al}, \mathrm{Cu}$, and $\mathrm{Br}$ [27-30].

\begin{tabular}{cccc}
\hline Property & Aluminum & Copper & Brass \\
\hline Yield Stress, $A(\mathrm{MPa})$ & 67.4 & 90 & 80 \\
Strength Coefficient, $B(\mathrm{MPa})$ & 471 & 292 & 505 \\
Deformation Hardening, $n$ & 0.424 & 0.31 & 0.605 \\
Strain Rate Coefficient, $C$ & 0.003 & 0.025 & 0.29 \\
Temperature Exponent, $m$ & 2.519 & 1.09 & 1.68 \\
Strain Rate, $\dot{\varepsilon}_{0}(1 / \mathrm{s})$ & 1 & 1 & 1 \\
\hline
\end{tabular}

\section{Results and Discussion}

\subsection{Dome Height and Outer Diameter}

A series of shock wave experiments for metal deformation was carried out using a shock wave tube. Wherein, $\mathrm{Al}, \mathrm{Cu}$, and $\mathrm{Br}$ for single $1.5 \mathrm{~mm}$ thickness and stacked metal sheets with $0.5 \mathrm{~mm}$ thickness for different combinations with $138 \mathrm{~mm}$ outer diameter were included. The pressure of shock wave front acting on the workpiece was approximately 37-39 bar (3.7-3.9 MPa). The blank sits perfectly into a die, with a depth size $26.5 \mathrm{~mm}$. Since the process takes place in a very short interval of time with very high pressure, a wrinkle can be formed on the skirt of the workpiece due to a small tolerance (or gap). To minimize the wrinkles, we placed a thin plastic sheet in between the plate in the experiments as well as in the simulations. Figure 6 represents the qualitative comparison of deformed metal sheets in the experiment and the numerical simulation of single Al with $1.5 \mathrm{~mm}$ thickness, three stacked metal sheets of $\mathrm{Al}$ and $\mathrm{Al}-\mathrm{Cu}-\mathrm{Br}$ combination of $0.5-\mathrm{mm}$ thickness. Numerical simulations studies show remarkable similarity with the experimental results, and nearly no wrinkles were observed on numerical simulations as well as experiments, on the skirts of the deformed plate.

(a) Al: $1.5 \mathrm{~mm}$ single plate
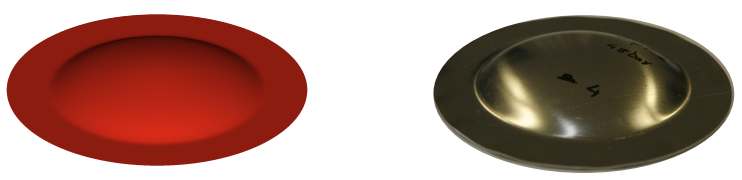

(b) Al: $0.5 \mathrm{~mm}$ stacked plates
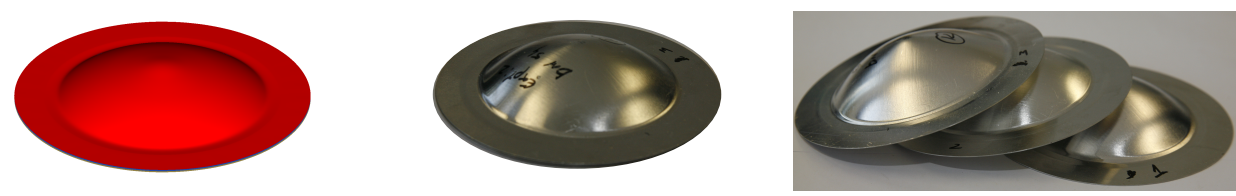

(c) Al-Cu-Br: 0.5 stacked plates
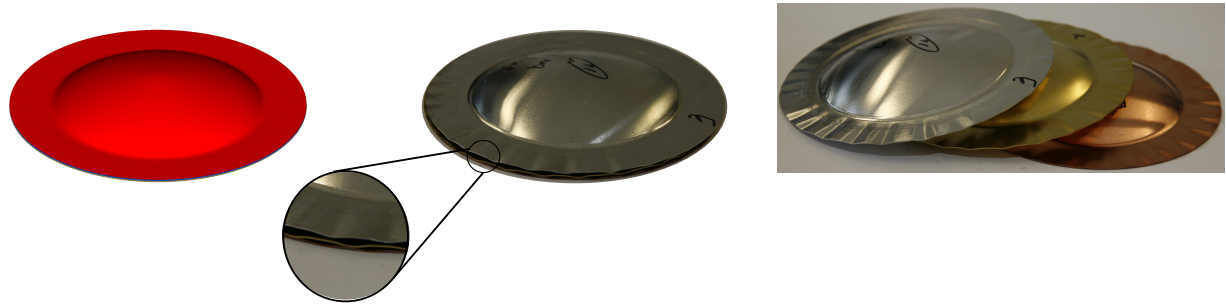

Figure 6. Qualitative comparison of the deformed metal between the experiments and the numerical simulations for (a) $1.5 \mathrm{~mm}$ single plate of $\mathrm{Al}$, (b) $0.5 \mathrm{~mm}$ stacked plates of $\mathrm{Al}$ and (c) $0.5 \mathrm{~mm}$ stacked plates of Al-Cu-Br. 
Figure 7 shows a comparison of dome height of the deformed metal sheets of $1.5-\mathrm{mm}$ thickness in the experiments and numerical simulations. To take into account the variation in the results, we have performed a minimum of four experimental tests for every analysis. Here, the average mean value of four tests is plotted with standard error deviation bar. The numerical simulation results were in excellent agreement with the experiments. Figure 8 represents a comparison of dome height of the deformed metal sheets of $0.5-\mathrm{mm}$ thicknesses with different sequences in the experiments and numerical simulations. The arrangement of samples was in the form of top-middle-bottom, wherein shock front first hits the top plate, and the bottom plate at the end.

From Figures 7 and 8, the average mean value of experiments and simulations of a single $\mathrm{Al}$ sheet of $1.5 \mathrm{~mm}$ thickness was nearly $15.7 \mathrm{~mm}$, whereas stacked three metal sheets of $0.5-\mathrm{mm}$ thickness of the same material was nearly $22 \mathrm{~mm}$. However, $\mathrm{Cu}$ and $\mathrm{Br}$ workpieces showed no significant change in deformation with single 1.5 and stacked $0.5 \mathrm{~mm}$ plates. In case of stacked metal sheets with a different combination, the dome height varies in the same range between 13 and $15 \mathrm{~mm}$ in the simulations as well as in experiments, which implies that in any combination we get nearly the same dome height of deformed metal sheets. Therefore, with the combination of different materials as well as an increase in a number of stacked plates, the combined formability of stacked plates also increases.

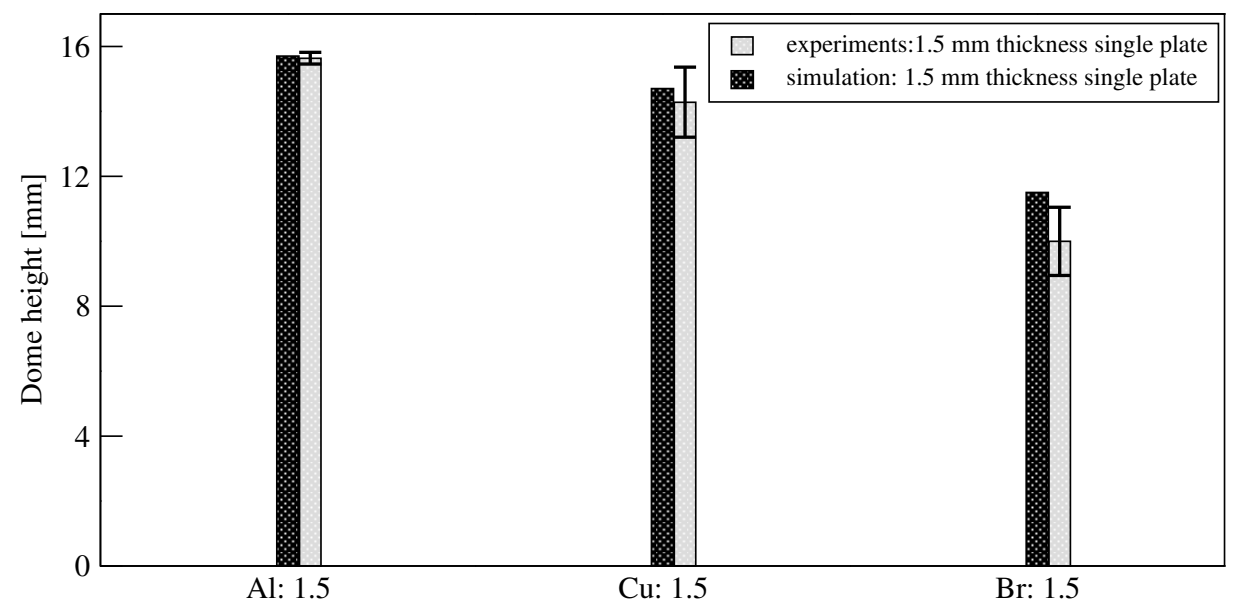

Figure 7. Comparison of dome height of the deformed metal sheets of $0.5-\mathrm{mm}$ thicknesses with different sequences in the experiments and numerical simulations.

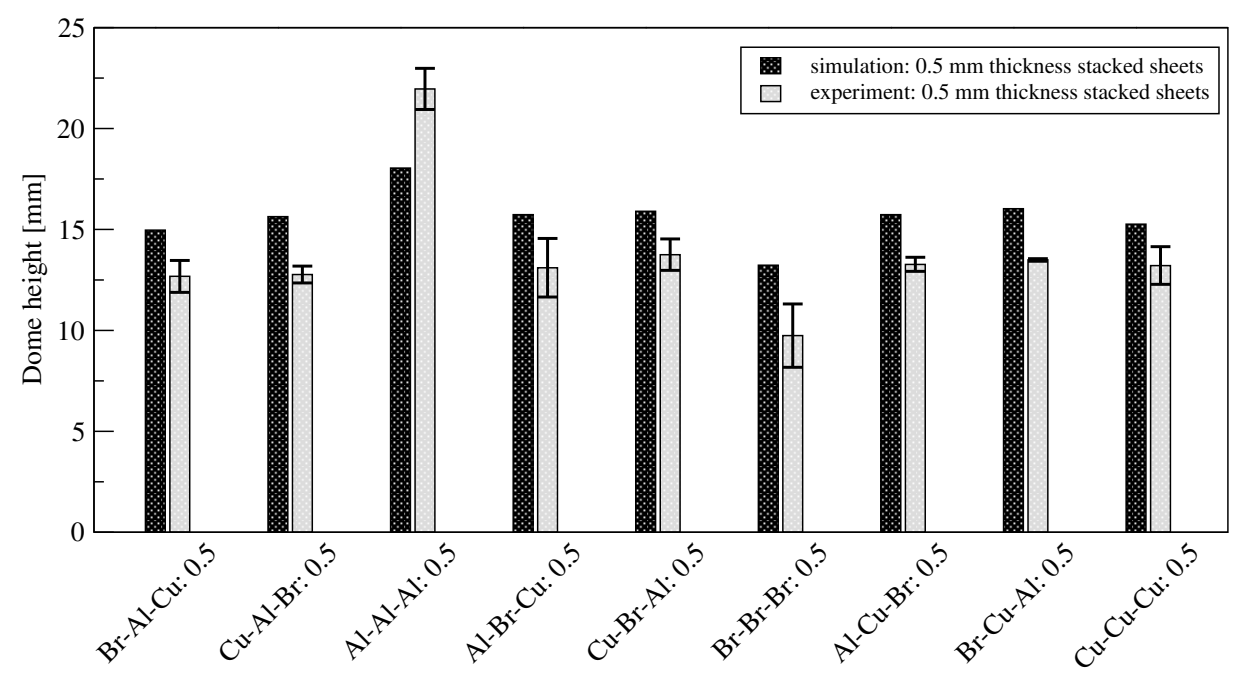

Figure 8. Comparison of dome height of a deformed metal in the experiment and numerical simulation for $0.5 \mathrm{~mm}$ thickness sheets. 
Figure 9 represents the qualitative and quantitative comparison of deformed specimen diameters in the experiment, and numerical simulations for single $\mathrm{Al}$ with $1.5 \mathrm{~mm}$ thickness, stacked three sheets of $\mathrm{Al}$ with $0.5 \mathrm{~mm}$ thickness and the stack of $\mathrm{Al}-\mathrm{Cu}-\mathrm{Br}$ metal sheets. Figure 10 shows the bar graph of the diameter of deformed workpieces. The experimental results are in good agreement with numerical simulations. For a single and stacked metal plates with a diameter of $138 \mathrm{~mm}$ in an undeformed state, the obtained outer diameter after deformation was in the range of $135-136.5 \mathrm{~mm}$, which was nearly same for all.

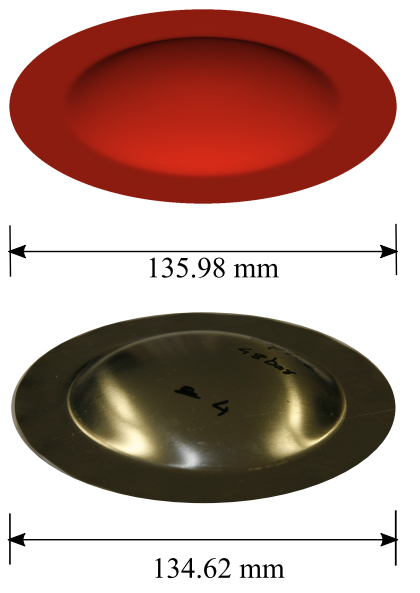

(a) $\mathrm{Al}: 1.5 \mathrm{~mm}$
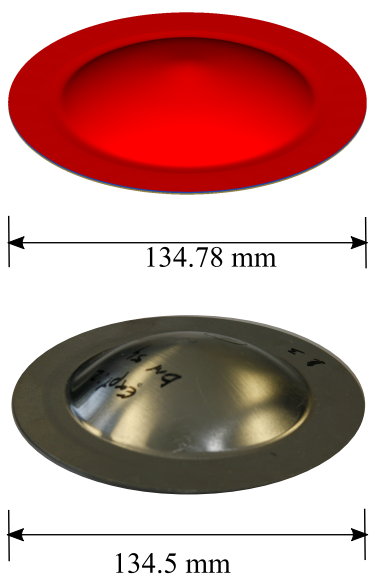

(b) Al: $0.5 \mathrm{~mm}$
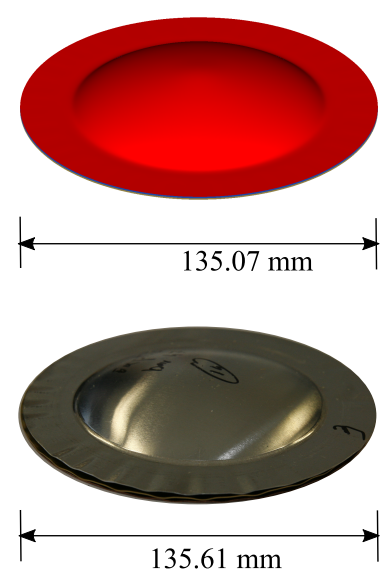

(c) Al-Cu-Br: $0.5 \mathrm{~mm}$

Figure 9. Diameter comparison of the deformed sheets between the experiments and numerical simulations for (a) $1.5 \mathrm{~mm}$ single plate of $\mathrm{Al}$, (b) $0.5 \mathrm{~mm}$ stacked plates of $\mathrm{Al}$ and (c) $0.5 \mathrm{~mm}$ stacked plates of Al-Cu-Br.

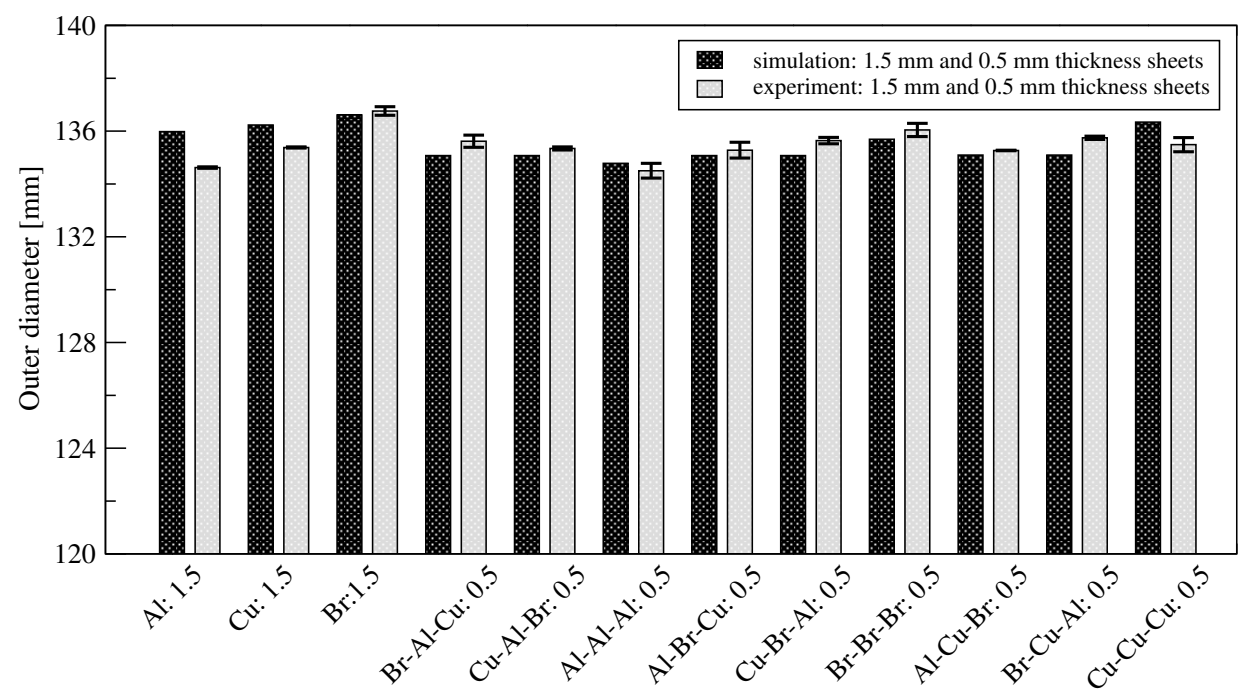

Figure 10. Diameter comparison of numerically- and experimentally-deformed single and stacked metal sheets.

\subsection{Thickness Distribution}

The thickness and the strain distribution are mainly dependent on a peak pressure load acting on a metal sheet. Moreover, the loading rate in the numerical model is very sensitive, even a little change in a load can affect the extreme change in model results. Therefore, we used the precisely same experimental loading curve in numerical simulations using well calibrated measuring devices [21-23]. 
One of the goals of this work was to study the thickness distribution in the numerical simulations and experiments.

\subsubsection{A Single Metal Sheet}

Figure 11a illustrates the quantitative representation of the thickness distribution for simulation and experimental results of a single $\mathrm{Al}, \mathrm{Cu}$ and $\mathrm{Br}$ metal sheets. The comparison between the experiments and simulations studies of thickness distribution shows that the variation patterns and thickness values were well in agreement. The minimum thickness obtained from the simulation of $\mathrm{Al}, \mathrm{Cu}$, and $\mathrm{Br}$ were $1.41 \mathrm{~mm}, 1.44 \mathrm{~mm}$ and $1.48 \mathrm{~mm}$, respectively. The minimum thickness for $\mathrm{Al}$ was at the center part of the plate area, however, in cases of $\mathrm{Cu}$ and $\mathrm{Br}$ minimum thicknesses were near the area of die curvature. The experimental minimum thickness values as well as their positions were nearly as like numerical simulations. Due to the circumferential stresses, the thickness was increased towards the outer area of the plate (radial pulling), where it was placed between a holder and die.

(a)

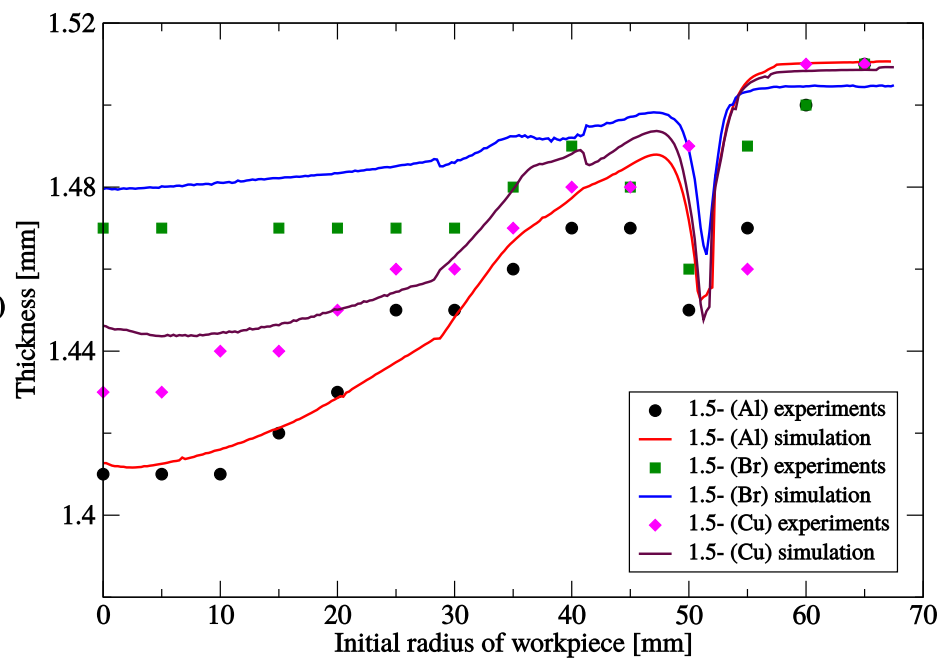

$\mathrm{Al}: 1.5 \mathrm{~mm}$

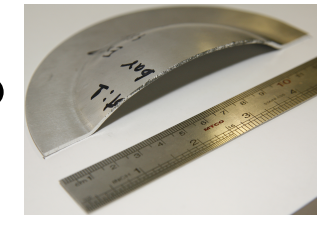

(c)

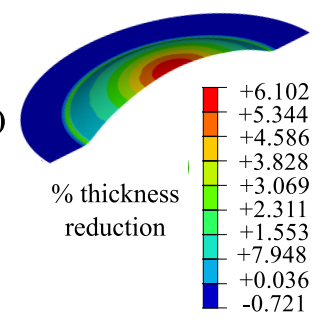

Br: $1.5 \mathrm{~mm}$
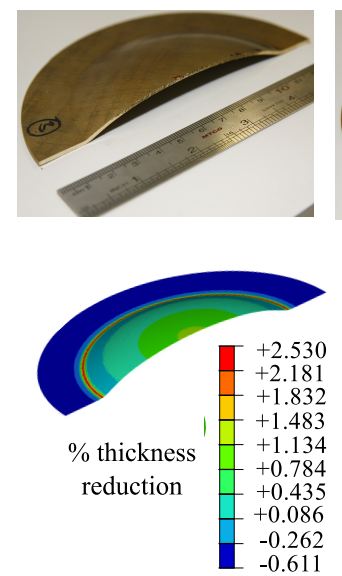

$\mathrm{Cu}: 1.5 \mathrm{~mm}$
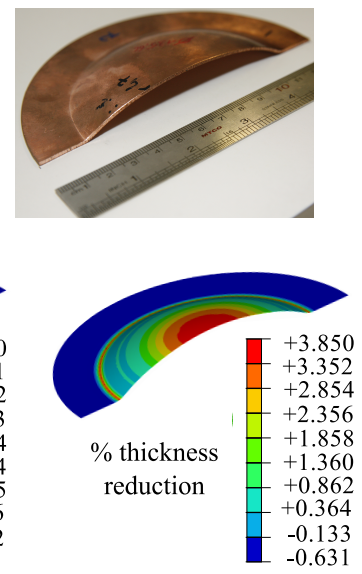

Figure 11. (a) Thickness variation in the $1.5 \mathrm{~mm}$ single deformed plate with respect to the initial radius of the workpiece. (b) Experimental and (c) numerical half section view of thickness distribution.

\subsubsection{Stacked Metal Sheets}

Figure 12 represents the thickness distribution for the $0.5 \mathrm{~mm}$ stacked metal sheets of the same material, and Figure 13 represents the thickness distribution for three different combinations. The minimum thickness was observed at the center of the sheets. From the simulations, it was in the range between 0.469 and $0.475 \mathrm{~mm}$ for all the combinations of stacked metallic sheets. The smooth 
thickness distribution was observed, however, at the die curvature area nearly 5-6\% reduction in thickness was observed. The experimental results followed the same trend of distribution as like simulation. In the experiments, in the center area of the sheets, the minimum thickness was between 0.464 and $0.477 \mathrm{~mm}$ for all combination of metal sheets. In the simulations, due to radial pulling, increase in thickness was observed near the outer area of the sheets; however, that increase was not significant.

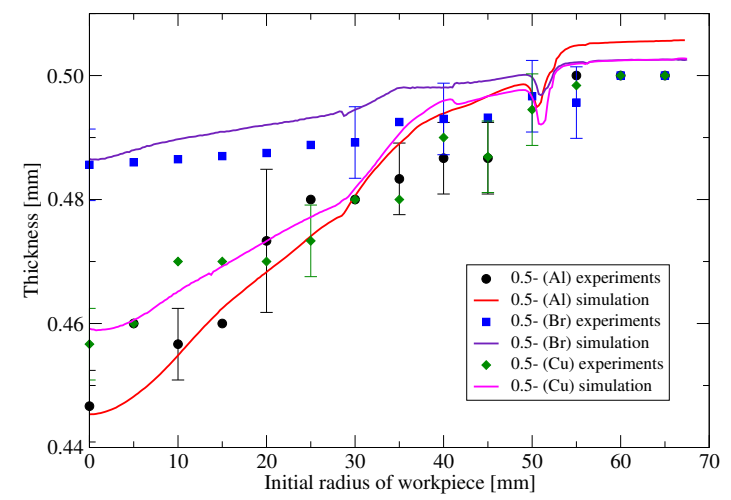

Figure 12. Thickness variation of the deformed $0.5 \mathrm{~mm}$ stacked metal sheets of $\mathrm{Al}, \mathrm{Cu}$ and $\mathrm{Br}$ materials with respect to the initial radius of the workpiece.

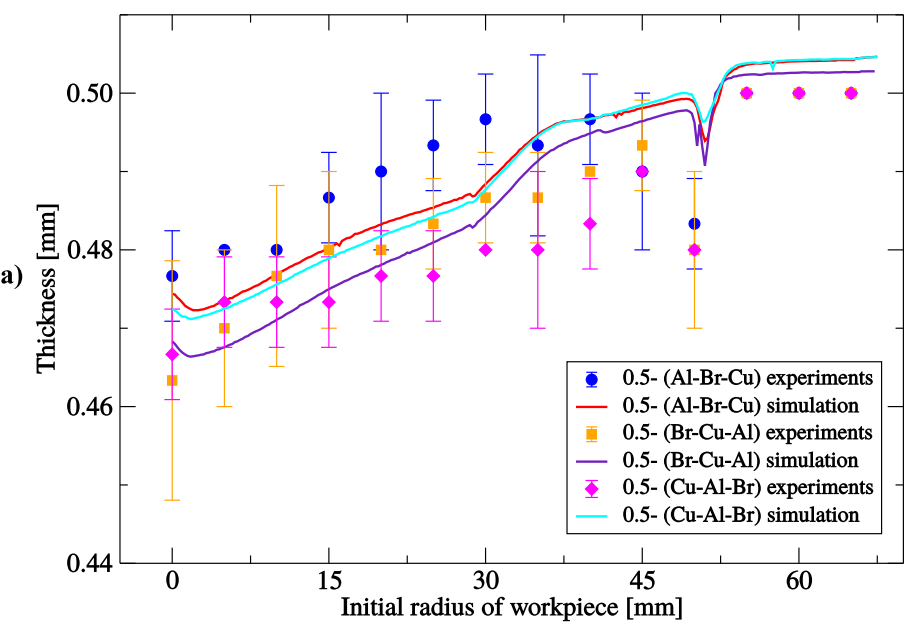

Al-Br-Cu: $0.5 \mathrm{~mm}$

(b)

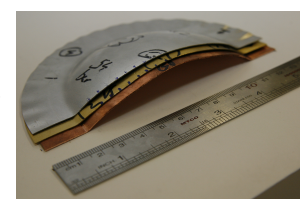

(c)

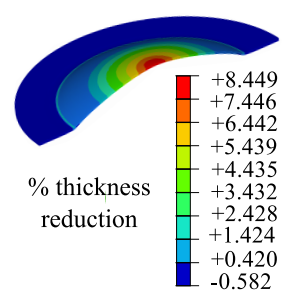

Br-Cu-Al: $0.5 \mathrm{~mm}$
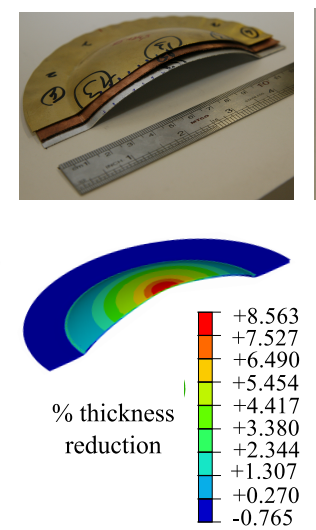

$\mathrm{Cu}-\mathrm{Al}-\mathrm{Br}: 0.5 \mathrm{~mm}$
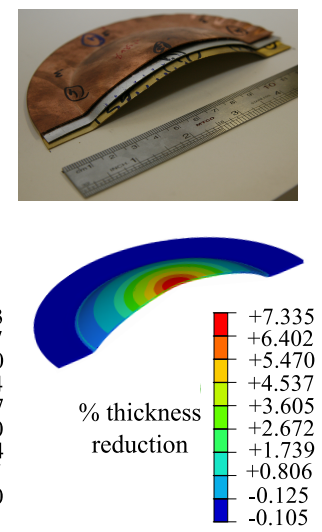

Figure 13. (a) Thickness variation of the deformed $0.5 \mathrm{~mm}$ stacked metal sheets with respect to the initial radius of workpiece. Snapshots of half sectional views of deformed stacked metal sheets in (b) experiments and (c) numerical simulations. 
It can be seen that simulations nearly verified experimental results. In case of stacked metallic sheets, thickness distribution was smoother compared to a single $1.5 \mathrm{~mm}$ thickness sheet. Due to different combinations of metal sheets and four experiments for every combination, the experimental measurement of thickness showed high variation.

\subsection{Strain Distribution}

Figure 14 shows strain distribution in numerical simulations. It represents the sequence of different snapshots at a different interval of the time during the deformation process. At time $t=1.5 \mathrm{~ms}$, the maximum strain of 0.1313 at the area of a die curvature and the minimum strain of 0.0145 at the outer area of the sheet were observed for a single Al metal sheet of thickness $1.5 \mathrm{~mm}$ (see Figure 14a). Moreover, for $\mathrm{Al}$ stacked metal sheets of $0.5 \mathrm{~mm}$ thickness, the maximum strain of 0.1288 at the center part of the sheets and the minimum strain of 0.0143 at the outer area of the plate were observed (see Figure 14b). Furthermore, in case of stacked metal sheets of Al-Br-Cu combination, for $\mathrm{Al}$ and $\mathrm{Cu}$ (top and bottom sheet), the maximum strain was at the center area as well as near the area of die curvature, and the minimum strain was at the center area of the sheets (see Figure 14c).

(a) Al: $1.5 \mathrm{~mm}$ thickness single plate

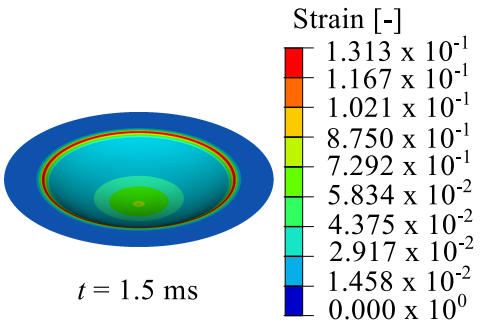

(b) Al: $0.5 \mathrm{~mm}$ thickness 3 plates

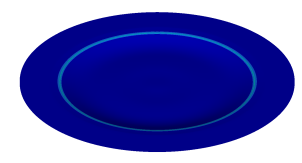

$t=0.1 \mathrm{~ms}$

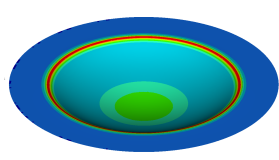

$t=0.6 \mathrm{~ms}$

$t=1.5 \mathrm{~ms}$

Strain [-]

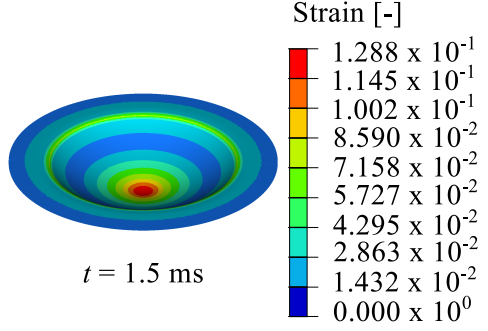

(c) Al-Br-Cu: $0.5 \mathrm{~mm}$ thickness 3 plates

Strain [-]

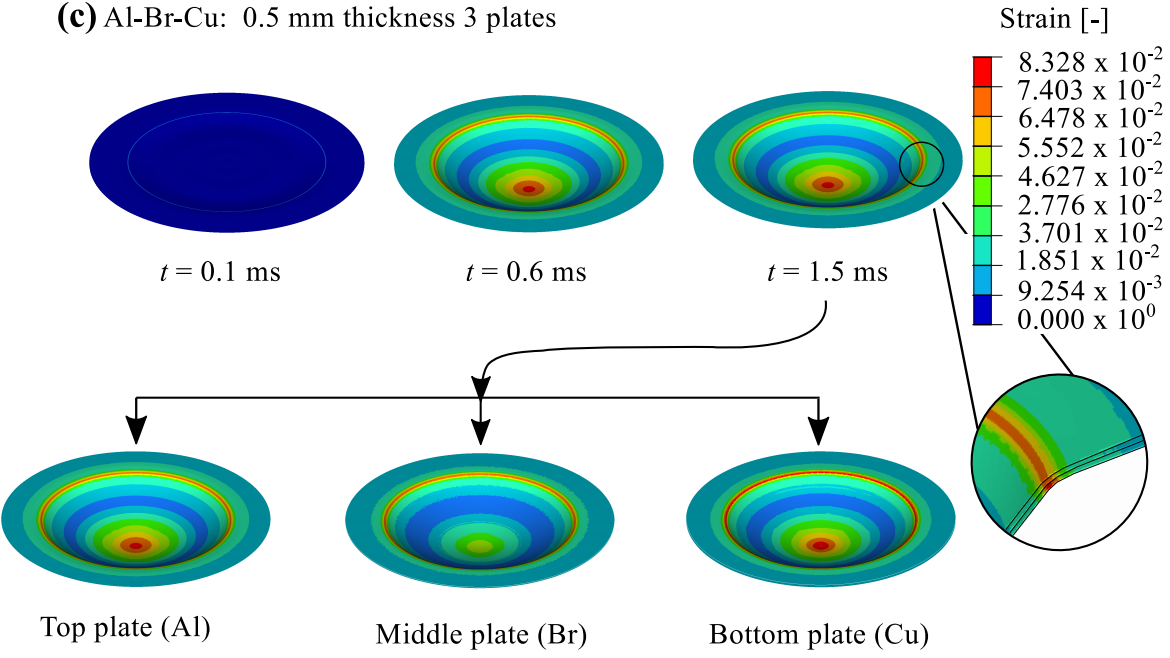

$t=0.1 \mathrm{~ms}$

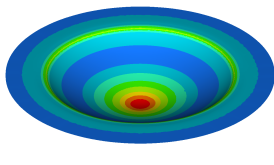

$t=0.6 \mathrm{~ms}$

$0.000 \times 10^{0}$

Figure 14. Effective strain distribution of (a) a single metal sheet of $\mathrm{Al}$, (b) three stacked sheets of $\mathrm{Al}$ and (c) combination of $\mathrm{Al}-\mathrm{Br}-\mathrm{Cu}$ in numerical simulations. 
Due to the maximum deformation of the stacked metal sheets of $\mathrm{Al}$ at the center area, the dome height was higher compared to a single Al sheet. Therefore, the variation of the strain from the edge to center in case of stacked sheets shows nearly smoother than a single sheet. Finally, the combination shows the combined variation of strain distribution of a single and stacked sheets.

\subsection{Stress Distribution}

Figure 15 represents a comparison of stress distribution of deformed metal sheets using numerical simulations. In case of a single Al sheet with a thickness of $1.5 \mathrm{~mm}$ and at the time $t=1.5 \mathrm{~ms}$, the maximum stress of $0.2 \mathrm{GPa}$ was observed near the area of die curvature, and the minimum stress of $0.088 \mathrm{GPa}$ was observed towards the outer area of the sheet. Whereas, for Al stacked sheets of $0.5 \mathrm{~mm}$ thickness, the maximum stress of $0.2 \mathrm{GPa}$ was observed at the area of the die curvature as well as at the center area of the sheets. For the combined Al-Cu-Br stacked sheets, stress behavior of the top and bottom sheets were nearly similar to Al stacked metallic sheets; however, the middle sheet showed the maximum stress at the center area (see Figure 15c).

$$
t=0.2 \mathrm{~ms} \quad t=0.6 \mathrm{~ms} \quad t=1.5 \mathrm{~ms}
$$

(a) $\mathrm{Al}: 1.5 \mathrm{~mm}$ thickness single plate
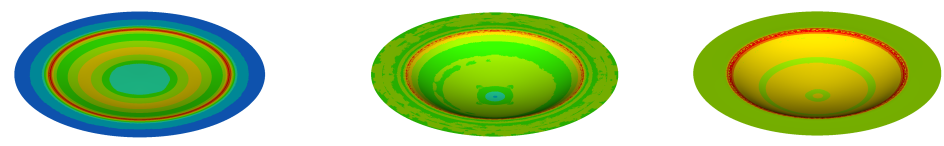

(b) Al: $0.5 \mathrm{~mm}$ thickness 3 plates
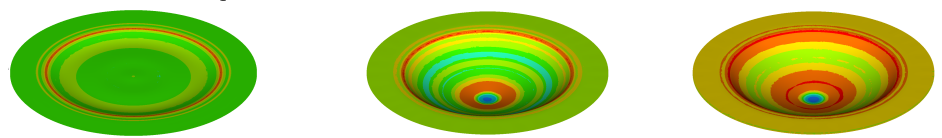

Stress [Gpa]

$2.000 \times 10^{-1}$

$1.778 \times 10^{-1}$

$1.556 \times 10^{-1}$

$1.333 \times 10^{-1}$

$1.111 \times 10^{-1}$
$-8.889 \times 10^{-2}$

$8.889 \times 10^{-2}$
$6.667 \times 10^{-2}$

$4.444 \times 10^{-2}$

(c) $\mathrm{Al}-\mathrm{Br}-\mathrm{Cu}: 0.5$ thickness 3 plates
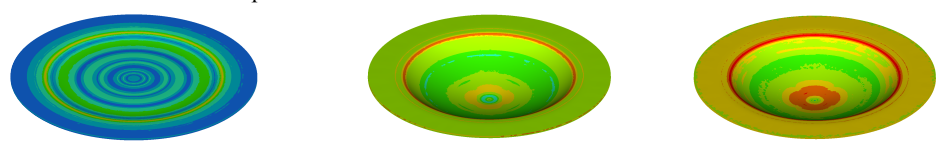

$2.222 \times 10^{-2}$

$0.000 \times 10^{0}$

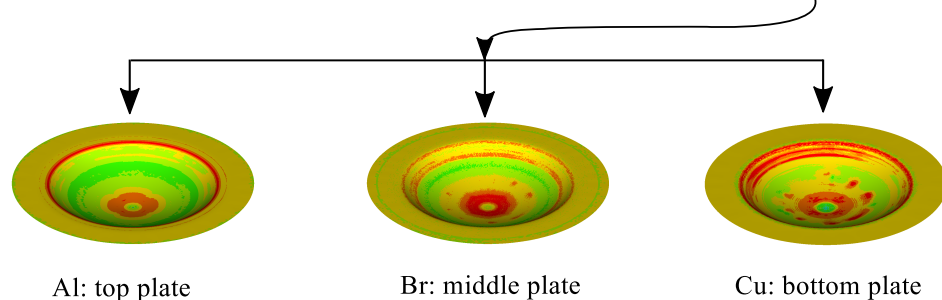

Figure 15. Comparison of von Mises stress distribution for a deformed metal using numerical simulations. (a) Al $1.5 \mathrm{~mm}$ thickness a single sheet, (b) Al $0.5 \mathrm{~mm}$ thickness stacked sheets and (c) Al-Br-Cu $0.5 \mathrm{~mm}$ thickness stacked sheets.

\section{Conclusions and Future Work}

The deformation of a single sheet and stacked sheets of aluminum, copper and brass materials using high-speed forming shock tube experiments was investigated. Moreover, the deformation of metal sheets was studied using finite element simulations. The dome height, outer diameter, and distributions of thickness, strain, and stress were investigated using numerical simulations and compared with experimental results.

The stacked metal sheets of aluminum of $0.5-\mathrm{mm}$ thickness have excellent formability and smoothness in thickness, strain and stress distributions compared to a single sheet of 1.5-mm thickness. This is due to the fact that the stacked metallic sheets have low intermetallic friction compared to a cohesive property of a single sheet. Moreover, the stacked metal sheets of copper and brass of $0.5-\mathrm{mm}$ 
thickness have excellent smoothness in thickness, strain and stress distributions compared to a single sheet of $1.5-\mathrm{mm}$ thickness. For example, the average mean value of experiments and simulations a single Al sheet of $1.5-\mathrm{mm}$ thickness was nearly $15.7 \mathrm{~mm}$, whereas for $0.5 \mathrm{~mm}$ thickness stacked three metal sheets of the same material was nearly $22 \mathrm{~mm}$. Moreover, for the stacked metal sheets with different combinations of $\mathrm{Al}, \mathrm{Cu}$ and $\mathrm{Br}$ show dome height deformation in the range between 13 and 15 $\mathrm{mm}$ by simulation as well as experiments, which implies that combined deformation is an average of formabilities of involved materials. Furthermore, it is concluded that there was no thickness reduction, strain or stress concentration at the die curvature (which lead to failure with further loading) in case of stacked metallic sheets.

In summary, the results obtained here clearly indicate that the shock wave-forming process is a feasible technique for mass production of stacked metal sheets as well as fabricating a hierarchical composite structure, which provides higher formability and smooth thickness distribution compared to a single material. The obtained numerical simulations studies showed remarkable similarity with the experimental results in case of deformation, final depth height, diameter, thickness, strain and stress distribution.

Due to a multilayered brick-and-mortar architecture of natural nacre material, it has extraordinary mechanical properties, e. g., high stiffness, and toughness. Inspired by this composite material, we propose that the stacked metal sheets of different stiffnesses glued together to form a composite material, which will have a high value of stiffness and fracture toughness. Figure 16 shows the proposed composite model. From the present work, it is clear that it is possible to conduct high-speed forming experiments as well as numerical simulations on the proposed composite material to study its mechanical properties and behavior.

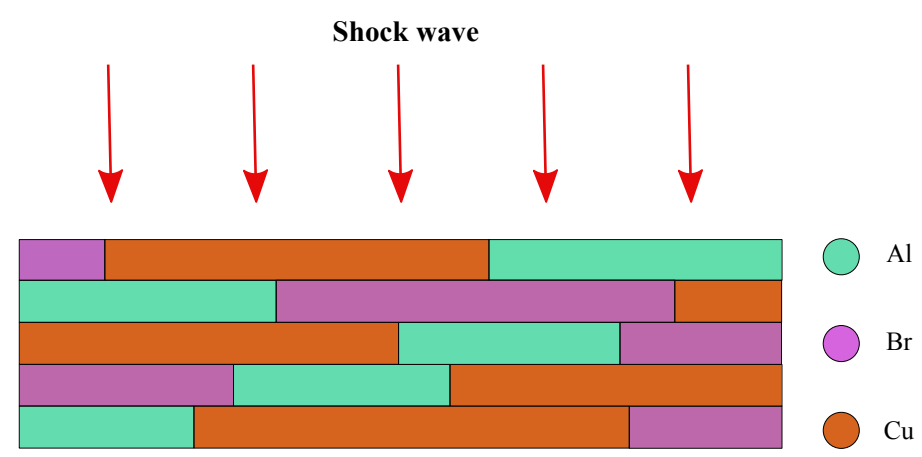

Figure 16. Schematic illustrations of nacre-like composite.

Author Contributions: Conceptualization, S.P.P. and B.M.; Methodology, S.P.P., R.M. and N.S.; Software, R.M.; Validation, S.P.P. and N.S.; Data Analysis, S.P.P., R.M. and N.S.; Investigation, S.P.P., R.M., N.S. and B.M.; Writing-Original Draft Preparation, S.P.P. and R.M.; Writing-Review \& Editing, S.P.P. and N.S.

Funding: This research received no external funding.

Acknowledgments: We thank Mario Hackbarth and Fabian Obstoj (Institute of General Mechanics, RWTH Aachen University) for the technical support during the experiments.

Conflicts of Interest: The authors declare no conflict of interest.

\section{References}

1. Meyers, M.A. Dynamic Behaviour of Materials; John Wiley and Sons, Inc.: New York, NY, USA, 1994.

2. Anderson, J.D. Modern Compressible Flow, with Historical Prospective; McGraw-Hill: New York, NY, USA, 1990.

3. Assehton, R. History of Explosives; Institute of Makers of Explosives: New York, NY, USA, 1940.

4. Jagadeesh, G.; Takayama, K. Novel applications of shock waves in biological sciences. J. Indian Inst. Sci. 2002, 82, 49-57.

5. Mynors, D.; Zhang, B. Applications and capabilities of explosive forming. J. Mater. Process. Technol. 2002, 125, 1-25. [CrossRef] 
6. Bruschi, S.; Altan, T.; Banabic, D.; Bariani, P.; Brosius, A.; Cao, J.; Ghiotti, A.; Khraisheh, M.; Merklein, M.; Tekkaya, A. Testing and modelling of material behaviour and formability in sheet metal forming. CIRP Ann. Manuf. Technol. 2014, 63, 727-749. [CrossRef]

7. Kumar, P.; LeBlanc, J.; Stargel, D.S.; Shukla, A. Effect of plate curvature on blast response of aluminum panels. Int. J. Impact Eng. 2012, 46, 75-85. [CrossRef]

8. Ray, N.; Jagadeesh, G.; Suwas, S. Response of shock wave deformation in AA5086 aluminum alloy. Mater. Sci. Eng. A 2015, 622, 219-227. [CrossRef]

9. Duan, Q.; Xiao, H.; Gao, W.; Shen, X.; Wang, Q.; Sun, J. Experimental investigation on shock waves generated by pressurized gas release through a tube. J. Loss Prev. Process Ind. 2015, 36, 39-44. [CrossRef]

10. Reddy, C.J.; Madhu, V. Dynamic behaviour of foams and sandwich panels under shock wave loading. J. Loss Prev. Process Ind. 2017, 173, 1627-1634. [CrossRef]

11. Ruan, L.; Ezaki, S.; Masahiro, F.; Shen, S.; Kawamura, Y. Forming of magnesium alloy by underwater shock wave. J. Magnes. Alloys 2016, 4, 27-29. [CrossRef]

12. Louar, M.; Belkassem, B.; Ousji, H.; Spranghers, K.; Kakogiannis, D.; Pyl, L.; Vantomme, J. Explosive driven shock tube loading of aluminium plates: Experimental study. Int. J. Impact Eng. 2015, 86, 111-123. [CrossRef]

13. Nagaraja, S.; Prasad, J.; Jagadeesh, G. Theoretical-experimental study of shock wave-assisted metal forming process using a diaphragmless shock tube. Proc. Inst. Mech. Eng. Part G J. Aerosp. Eng. 2012, 226, 1534-1543. [CrossRef]

14. Atrian, A.; Fereshteh-Saniee, F. Deep drawing process of steel/brass laminated sheets. Compos. Part B Eng. 2013, 47, 75-81. [CrossRef]

15. Andreotti, R.; Colombo, M.; Guardone, A.; Martinelli, P.; Riganti, G.; di Prisco, M. Performance of a shock tube facility for impact response of structures. Int. J. Non-Linear Mech. 2015, 72, 53-66. [CrossRef]

16. Justusson, B.; Pankow, M.; Heinrich, C.; Rudolph, M.; Waas, A. Use of a shock tube to determine the bi-axial yield of an aluminum alloy under high rates. Int. J. Impact Eng. 2013, 58, 55-65. [CrossRef]

17. Aune, V.; Fagerholt, E.; Langseth, M.; Børvik, T. A shock tube facility to generate blast loading on structures. Int. J. Prot. Struct. 2016, 7, 340-366. [CrossRef]

18. Aune, V.; Valsamos, G.; Casadei, F.; Langseth, M.; Børvik, T. On the dynamic response of blast-loaded steel plates with and without pre-formed holes. Int. J. Impact Eng. 2017, 108, 27-46. [CrossRef]

19. Stoffel, M.; Schmidt, R.; Weichert, D. Shock wave-loaded plates. Int. J. Solids Struct. 2001, 38, 7659-7680. [CrossRef]

20. Stoffel, M. An experimental method to validate viscoplastic constitutive equations in the dynamic response of plates. Mech. Mater. 2005, 37, 1210-1222. [CrossRef]

21. Patil, S.P.; Popli, M.; Jenkouk, V.; Markert, B. Numerical modelling of the gas detonation process of sheet metal forming. J. Phys. Conf. Ser. 2016, 734, 032099. [CrossRef]

22. Jenkouk, V.; Patil, S.; Markert, B. Joining of tubes by gas detonation forming. J. Phys. Conf. Ser. 2016, 734, 032101; IOP Publishing. [CrossRef]

23. Patil, S.P.; Prajapati, K.G.; Jenkouk, V.; Olivier, H.; Markert, B. Experimental and numerical studies of sheet metal forming with damage using gas detonation process. Metals 2017, 7, 556. [CrossRef]

24. Ben-Dor, G.; Igra, O.; Elperin, T. (Eds.) Handbook of Shock Waves, Three Volume Set; Academic Press: San Diego, CA, USA, 2001.

25. Hallquist, J.O. LS-DYNA Theory Manual; Livermore Software Technology Corporation: Livermore, CA, USA, 2006.

26. Lampman, S. ASM Handbook; ASM International: Materials Park, OH, USA, 1990.

27. Johnson, G.R.; Cook, W.H. A constitutive model and data for metals subjected to large strains, high strain rates and high temperatures. In Proceedings of the 7th International Symposium on Ballistics, Hague, The Netherlands, 19-21 April 1983; Volume 21, pp. 541-547.

28. Smerd, R.; Winkler, S.; Salisbury, C.; Worswick, M.; Lloyd, D.; Finn, M. High strain rate tensile testing of automotive aluminum alloy sheet. Int. J. Impact Eng. 2005, 32, 541-560. [CrossRef]

29. Ding, H.; Shen, N.; Shin, Y.C. Modeling of grain refinement in aluminum and copper subjected to cutting. Comput. Mater. Sci. 2011, 50, 3016-3025. [CrossRef]

30. Peroni, L.; Scapin, M.; Fichera, C.; Manes, A.; Giglio, M. Mechanical properties at high strain-rate of lead core and brass jacket of a NATO $7.62 \mathrm{~mm}$ ball bullet. In EPJ Web of Conferences; EDP Sciences: Les Ulis, France, 2012; Volume 26. 
31. Espinosa, H.D.; Patanella, A.J.; Fischer, M. Dynamic friction measurements at sliding velocities representative of high-speed machining processes. J. Tribol. 2000, 122, 834-848. [CrossRef]

32. Hassan, M.A.; Ahmed, K.I.E.; Takakura, N. A developed process for deep drawing of metal foil square cups. J. Mater. Process. Technol. 2012, 212, 295-307. [CrossRef]

33. Mori, L.F.; Krishnan, N.; Cao, J.; Espinosa, H.D. Study of the Size Effects and Friction Conditions in Microextrusion-Part II: Size effect in dynamic friction for brass-steel pairs. J. Manuf. Sci. Eng. 2007, 129, 677-689. [CrossRef]

34. Dhaiban, A.A.; Soliman, M.E.S.; El-Sebaie, M.G. Finite element modeling and experimental results of brass elliptic cups using a new deep drawing process through conical dies. J. Mater. Process. Technol. 2014, 214, 828-838. [CrossRef]

35. Liu, T. Sliding friction of copper. Wear 1964, 7, 163-174. [CrossRef]

36. Handbook ASM. Friction, Lubrication, and Wear Technology; ASM International: Materials Park, OH, USA, 1994.

37. Fu, M.W.; Yang, B.; Chan, W.L. Experimental and simulation studies of micro blanking and deep drawing compound process using copper sheet. J. Mater. Process. Technol. 2013, 213, 101-110. [CrossRef]

38. Chowdhury, M.A.; Nuruzzaman, D.M.; Mia, A.H.; Rahaman, M.L. Friction coefficient of different material pairs under different normal loads and sliding velocities. Tribol. Ind. 2012, 34, 18-23.

(c) 2018 by the authors. Licensee MDPI, Basel, Switzerland. This article is an open access article distributed under the terms and conditions of the Creative Commons Attribution (CC BY) license (http://creativecommons.org/licenses/by/4.0/). 